\title{
Modeling and Simulation of Faulty Squirrel Cage Induction Motor Using Magnet
}

\author{
S.Nagarajan and S.Rama Reddy
}

\begin{abstract}
Induction motors are widely used in industry as prime electro mechanical energy conversion devices. Consequently the condition monitoring and fault diagnosis of induction motors have received significant attention recently and become an integrated part of various maintenance strategies. This paper presents the modeling and simulation of fault diagnosis of 3-phase squirrel-cage induction motor using magnet. The cross section of the machine was modeled with finite elements, and the field distribution and magnetic performance were computed. The fault considered in this work is broken bar condition. Simulation is performed using magnet and the results are presented.
\end{abstract}

Index Terms-Induction Motor, MCSA, Broken bar, Finite Element Analysis.

\section{INTRODUCTION}

Monitoring fault detection and diagnosis of electrical machines are becoming more and more important issues in the field of electrical machines as new data processing technique and new technologies for electrical drives emerge. Induction machines can be found in almost all types of applications from small single-phase machines for home appliances up to large three phase motors for industrial plants. Machine monitoring plays a crucial role in detecting incipient faults and in this way, preventing unscheduled downtime and the associated outage costs of electromechanical systems and components. In past decades a number of different incipient fault detection methods and schemes have been presented. Special attention has been devoted to non-invasive methods, which are capable to detect faults using measured data without disassembling the machine and its structural parts. The MCSA (Motor Current Signature Analysis) can be classified as the most promising fault detection methods, as it permits to detect several common machine faults.

This method is based on the spectral decomposition of the steady state stator current, which can be acquired with simple measurement equipment and under normal operation of the machine.This is an important advantage when compared to other invasive methods.For the use of invasive methods it is in general necessary to insert some kind of sensor in the machine, as for the case of vibrations analysis or temperature analysis. In this way, considering the advantages and reduced costs, non-invasive methods have

S. Nagarajan is a Research Scholar, in the Jerusalem College of Engineering, Center for Collaborative research with Anna University, Chennai, India (Phone: 9444177170, Email : nagu_shola@yahoo.com).

S. Rama Reddy is a Professor in Electrical and Electronics Engineering Department, Jerusalem College of Engineering, Center for Collaborative research with Anna University, Chennai, India. (Email srr_victory@yahoo.com) been preferred for practical purposes

The above cited works were mainly developed from an experimental standpoint. However, accurate analysis of induction motor under faulted conditions is very difficult. Some works have then reported on the introduction of numerical methods to aid in understanding faults manifestation. Once known faults are accurately simulated, the technique can be used to predict how other, more difficult to identify, faults can be detected via MCSA. The finite element method, which is well established for induction motors modeling, could be used to provide an accurate evaluation of the magnet field distribution inside the motor. Perturbation in this field distribution would indicate fault presence, e.g. broken bars detection. To assess the magnetic saturation effect on faults detection, the timestepping finite element method is recommended.

\section{LITERATURE SURVEY}

An unsupervised, on-line system for Induction motor fault detection using stator current monitoring explains an over all scheme, based on current monitoring that utilizes both a rule based expert system and a neural network algorithm to determine if any one of fault condition is developing in an induction machine[1]. A Review of Induction motors signature analysis as a medium for faults detection introduce a fundamental theory, main results and practical application of motor current signature analysis for the detection and localization of abnormal electrical and mechanical condition motor[2]. Detection of broken bars in cage rotor on an Induction machine deals with broken bar fault and its detection technique[3].

Detection of broken rotor bars in induction motors using state and parameters estimation describes the detection of broken bars in induction motors using apparent rotor resistance[4]. Finite element Analysis of Induction motors based on computing detailed Equivalent circuit Parameters explains about the analysis of Induction motor by finite element analysis and the parameters are provided by the equivalent circuit[5]. Finite Element Analysis of three phase Induction motor: comparisons of two different approaches deals with fault analysis of Induction motor using finite element analysis[6]. Bearing damage detection using stator current monitoring explains in detail about the detection of bearing fault using MCSA method[7]. Online diagnosis of Induction motors using MCSA explains the identification of fault[8].Vibration and current monitoring for detecting airgap eccentricity in large Induction motors explain about the air-gap eccentricity and its fault detection methods[9]. The above literature does not deal with the simulation of faulty motor using magnet. An attempt is made in the present work to diagnose the faults using flux density curves in magnet software. 


\section{SOLID MODEL OF INDUCTION MOTOR}

Magnet uses the finite-element method to solve the field equations. For a 2D model, the entire region is subdivided into a mesh of triangular elements, and within each element the true field is approximated by a polynomial. The accuracy can be improved by increasing the order of the polynomial: this is one of the solver options. It can be further improved by using smaller elements in critical regions of the model, which is done automatically when the user sets the adaption options. With any numerical method, perfect accuracy is unattainable. Even with full use of the options for improving the accuracy, the solution generated by Magnet contains errors.

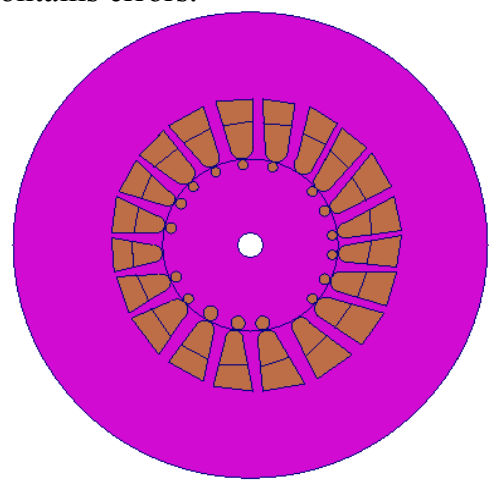

Figure 1. Solid model of induction motor

In most cases these errors will be insignificant, and are likely to be smaller than the changes caused by manufacturing tolerances or variations in the magnetic properties of the materials. Solid model of induction motor is shown in Fig1.

The above diagram represents the model of induction motor. This model is developed using MAGNET simulation tool. The various materials used for modeling the induction motor are listed in table 1.

TABLE 1. MATERIALS USED FOR MODELING OF INDUCTION MOTOR

\begin{tabular}{|l|l|}
\hline \multicolumn{1}{|c|}{ Part } & \multicolumn{1}{c|}{ Material } \\
\hline Stator and rotor core & Silicon steel \\
\hline Stator conductors and rotor bars & Copper \\
\hline Shaft hole & Air \\
\hline
\end{tabular}

\section{A. Discretisation of Solid Model of Induction Motor}

The essence of any variational method is to search directly for a function A (magnetic vector potential) that minimizes the functional instead of attempting to solve nonlinear Poisson's equation.

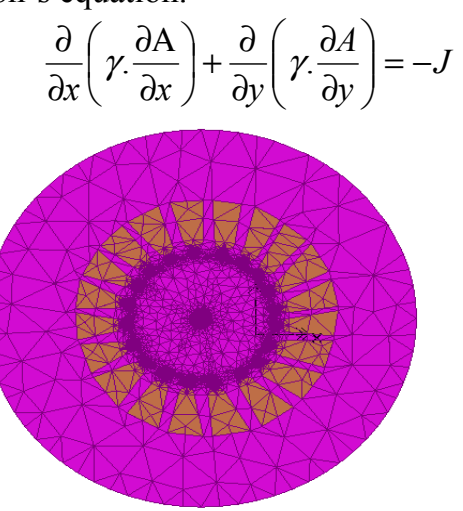

Figure 2. Discretisation of the Problem Region

The finite element technique is no exception. In order to search efficiently, however it is first necessary to discretise the problem.

Let the entire problem region be sub divided into triangles in any desired manner, ensuring only that all ironair interfaces coincide with triangle sides. Figure 2 shows one possible sub division of a problem region. It is observed that the number, shape and size of the triangles are not restricted in any way. Let an approximation to the function A be assumed in each triangle, depending only on the values of $A$ at the triangle vertices and possibly a few other points within the triangle. Take together, these approximation constitute an approximate representation for A every where in the region. The vertex values of $\mathrm{A}$ are now varied until the functional given by (1) reaches minimum.

Energy Functional

$$
F=\iiint_{R}\left(\int_{0}^{B} \gamma b \cdot d b\right) \cdot d a-\iint_{R} J \cdot A \cdot d a
$$

This is readily possible, since there exists only a finite number of vertex values. When a minimum is reached, the resulting approximation for A must be the best possible one in the least square sense.

\section{B. Magnetic Field Distribution for Healthy Motor}

Magnetic distribution for healthy motor is shown in Fig3a.The healthy motor shows the distribution of flux lines from north pole to south pole. The north pole in the model is considered by taking one side of the coils as positive values of current and negative values for South Pole. The variation of flux density with distance (in degrees) is shown in Figure 3b.

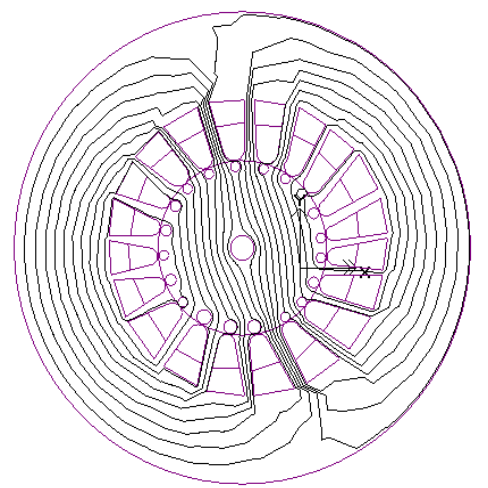

Figure 3a. Magnetic field distributions for healthy motor Contour Plót Fièld Circle Grạph

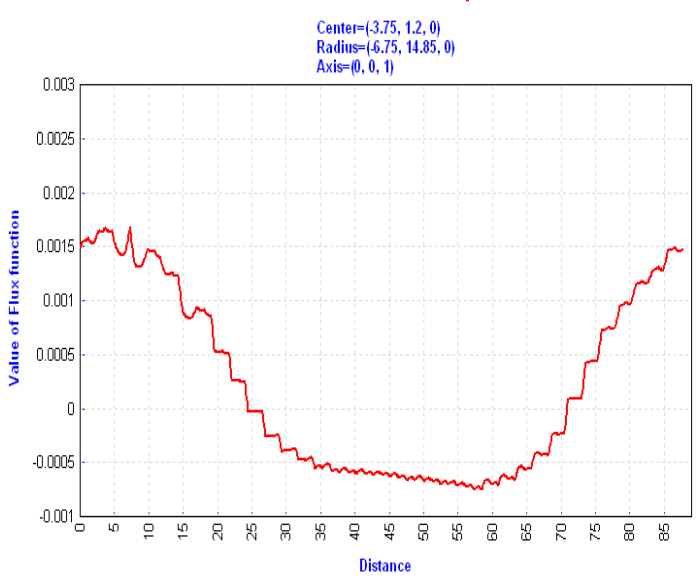

Figure 3b. Field Analysis for Healthy Motor 


\section{Magnetic Field Distribution for Five Broken Bars}

The magnetic field distribution for motor with five broken bars is shown in Figure 4a. The bars are considered to be broken by making the current of 5 bars as zero.

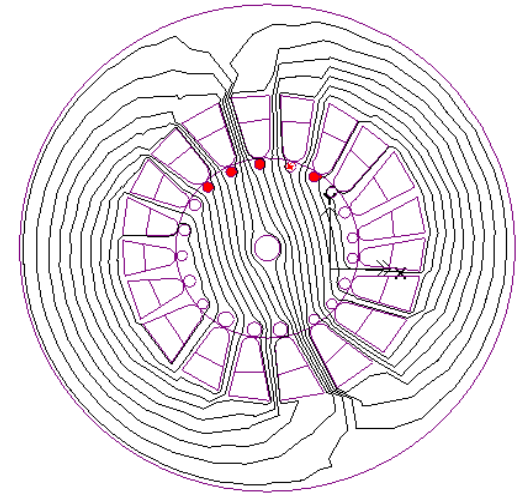

Figure 4a. Magnetic field distributions with five broken bars

The variation of flux density with distance (in degrees) for faulty motor is shown in figure $4 \mathrm{~b}$. The change in flux is higher in faulty motor than the healthy motor

Contour Plot Field Circle Graph

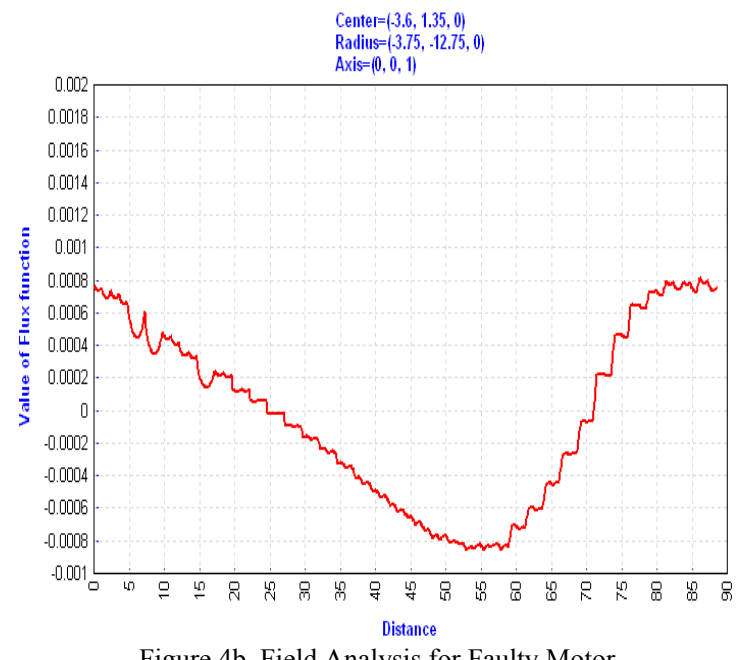

Figure 4b. Field Analysis for Faulty Motor

The simulation is done on the healthy and faulty model and the results are presented using plots showing variation of flux linkage with distance.

The simulation results of healthy and faulty motors are summarized in Table 2.The stored magnetic energy is reduced by $8 \%$ and the average flux density is reduced by $49 \%$ under faulty condition.

TABLE 2. SIMULATION RESULTS OF HEALTHY AND FAULTY MOTOR
\begin{tabular}{|l|l|l|}
\hline & Healthy Motor & Faulty Motor \\
\hline $\begin{array}{l}\text { Stored } \\
\text { magnetic } \\
\text { energy }\end{array}$ & 0.415042739 joules & 0.3826211 joules \\
\hline $\begin{array}{l}\text { Average } \\
\text { flux } \\
\text { density }\end{array}$ & $0.027451 \mathrm{wb} / \mathrm{m} 2$ & $0.01423 \mathrm{wb} / \mathrm{m} 2$ \\
\hline
\end{tabular}

\section{CONCLUSION}

This paper has investigated the feasibility of detecting broken bars using magnetic filed distribution of an induction machine. This fault causes variation in the flux density and stored magnetic energy. Fault detection system is simulated using MAGNET simulation tool and the flux density curves are presented. The magnetic energy and flux density are reduced in the faulty motor when compared with healthy motor. The simulation results are in line with the predictions.

\section{REFERENCES}

[1] R.R.Schoen et al., "An unsupervised, on-line system for Induction motor fault detection using stator current monitoring.," IEEE Trans. Ind. Applicats., vol.31, pp.1280-1286, Nov/Dec. 1995.

[2] Mohammed EI Hachemi Benbouzid., "A Review of Induction motors signature analysis as a medium for faults detection," IEE Trans. Ind. Elec, vol.47, no.5, pp.984-992, Oct.2000.

[3] N.M. Elkasatgy et al., "Detection of broken bars in cage rotor on an Induction machine,” IEEE Trans. Ind. Applicats., vol.28, pp. 165-171, Jan/Feb. 1992.

[4] K.Rae Cho,Jeffrey H,Lang and Stephen D.Umars, "Detection of broken rotor bars in induction motors using state and parameters estimation,"IEEE Transactions on industry application,vol.28,No.3,May/June1992.

[5] Ping Zhou, John Gilmore Zsolt Badics, Zoltan J.cendes., "Finite element Analysis of Induction motors based on computing detailed Equivalent circuit Parameters.," IEEE Trans. On Magnetics, vol. 34, no.5, pp.3499-3502 Sep 1988.

[6] N.Bianchi, S.Bolognaini, G.Comelato., "Finite Element Analysis of three phase Induction motor: comparisons of two different approaches.," IEEE Trans. Elec. Conversion, vol.14, no.4, pp.15231528, Dec 1999.

[7] Randy R. Schoen, Thomas G. Habtler, Farrukh kamran, Robert G. Bartheld, "Motor Bearing damage detection using stator current monitoring.," IEEE Trans. Ind. Applicat., vol.31 pp.1274-1279, Nov/Dec.1995.

[8] Jee-Hoon Jung, Jong-Jae Lee, and Bong-Hwan Kwon, "Online diagnosis of Induction motors using MCSA,” IEEE Trans. Ind. Elec. 53, no.6, pp.1842-1852, December 2006.

[9] J.R.Cameron et al., "Vibration and current monitoring for detecting air-gap eccentricity in large Induction motors.," Proc. Inst. Elect. Engg., pt. B, vol. 133, pp. 155-163, May 1986.

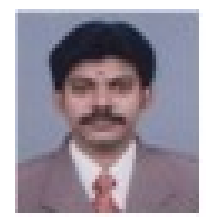

S. Nagarajan received his B.E. degree in Electrical \& Electronics Engineering from Sapthagiri College of Engineering, Chennai, India in 1998, M.E. degree in Power System from Anna University, Chennai, India in 2005. He has 12 years of teaching experience. He is presently a research scholar in Electrical and Electronics Engineering Department, Jerusalem College of Engineering, Collaborative Research Centre with Anna University, Chennai. His research interest is on the condition monitoring of 3-phase squirrel cage induction motor.

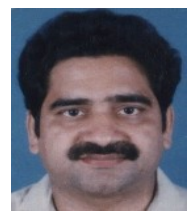

S.Rama Reddy is a professor in Electrical \& Electronics Engg. Department, Jerusalem College of Engineering, Chennai, India. He btained his M.E. in Power Systems from Anna University, Chennai and $\mathrm{Ph} . \mathrm{D}$ in the area of Power Electronics from Anna University, Chennai, India. $\mathrm{He}$ has published 40 technical papers in national and international conferences proceedings / journals. He has worked in Tata Consulting Engineers, Bangalore and Anna University, Chennai. He has 18 years of teaching experience. His research interests Society of India, Society of Power Engineers and include the areas of resonant converters and FACTS. $\mathrm{He}$ is life member of Institution of Engineers (India), Indian Society for Technical Education, Systems Institution of Electronics and Telecommunication Engineers (India). He has published text books on Power Electronics, Solid State Circuits and Electronic Circuits. 